9-5-2016

\title{
Copper(I) thiocyanate networks with aromatic diimine ligands
}

\author{
Gerardo Ayala \\ College of William and Mary \\ Tristan A. Tronic \\ College of William and Mary \\ Robert D. Pike \\ College of William and Mary, rdpike@wm.edu
}

Follow this and additional works at: https://scholarworks.wm.edu/aspubs

\section{Recommended Citation}

Ayala, Gerardo; Tronic, Tristan A.; and Pike, Robert D., Copper(I) thiocyanate networks with aromatic diimine ligands (2016). Polyhedron, 115, 257-263.

https://doi.org/10.1016/j.poly.2016.05.030

This Article is brought to you for free and open access by the Arts and Sciences at W\&M ScholarWorks. It has been accepted for inclusion in Arts \& Sciences Articles by an authorized administrator of W\&M ScholarWorks. For more information, please contact scholarworks@wm.edu. 


\title{
Copper(I) Thiocyanate Networks with Aromatic Diimine Ligands.
}

\author{
Gerardo Ayala, Tristan A. Tronic, and Robert D. Pike* \\ Department of Chemistry, College of William and Mary, Williamsburg, VA 23187.
}

\begin{abstract}
A total of five new CuSCN-LL complexes with aromatic diimine ligands, $L L=$ quinoxaline (Qox), quinazoline (Qnz), pthalazine (Ptz), 2-aminopyrazine (2- $\left.\mathrm{NH}_{2} \mathrm{Pyz}\right)$ ), and 2methoxypyrazine (2-MeOPyz) have been prepared and characterized by crystallographic methods. The following compounds are reported: $(\mathrm{CuSCN})_{2}(\mathrm{Qox})(\mathbf{1}),(\mathrm{CuSCN})(\mathrm{Qnz}) \quad(\mathbf{2}),(\mathrm{CuSCN})_{2}(\mathrm{Ptz}) \quad(3)$, $(\mathrm{CuSCN})_{2}\left(2-\mathrm{NH}_{2} \mathrm{Pyz}\right)(\mathbf{4})$, and $(\mathrm{CuSCN})(2-\mathrm{MeOPyz})(5)$. Compounds 1-4 were prepared using an extended aqueous reflux method in the presence of $\mathrm{KSCN}$ and ammonia. Compound $\mathbf{5}$ was prepared by directly reacting solid CuSCN with the liquid ligand. In complexes $\mathbf{2}$ and $\mathbf{5}$, LL is monodentate, while in others LL is bridging bidentate. All network structures are 2-D sheets, consisting of $\mu_{2}$-LL-crosslinked CuSCN ladders for $\mathbf{1}$ and 4, LL-decorated CuSCN sheets for $\mathbf{2}$ and $\mathbf{5}$, and unusual $\mu_{2}$-LL-"stapled" sheets for 3 .
\end{abstract}

Keywords: Copper thiocyanate complexes; Crystal structures; Diimine ligands; Network structures; Thermogravimetry 


\section{Introduction}

Polymeric and network metal-organic compounds are of interest owing to the wide array of structural motifs they exhibit and their potential applications in gas storage, chemical sensing, catalysis, and separations [1]. Among the advantages offered by metal-organic networks is their convenient formation via self-assembly. Thus, stoichiometrically controlled combinations of metals and ligands tend to react under relatively modest thermal conditions, often forming multiple and/or unexpected product topologies. In addition, insoluble products are readily isolated from reaction mixtures. Of particular interest are metal salts containing bridging inner sphere anions, such as halides, chalcogenides, or pseudohalides. These salts are themselves robust inorganic network-formers. Their networks can be further expanded through reaction with bridging organic ligands. In contrast, non-coordinating counterions, such as $\mathrm{BF}_{4}^{-}, \mathrm{PF}_{6}{ }^{-}, \mathrm{ClO}_{4}^{-}$, etc. tend to fill network pores, diminishing network host-guest potential.

Copper(I) thiocyanate is an example of an inner sphere salt, forming 3-D networks in each of its three known polymorphs [2]. In each $\mathrm{CuSCN}$ polymorph, tetrahedral coordination of $\mathrm{Cu}(\mathrm{I})$ is complemented by tetrahedral geometry at sulfur, resulting from $\mu_{3}$-bridging of copper centers. Because both copper and sulfur centers show tetrahedral connectivity, the polymorphs of CuSCN bear a close structural relationship to those of $\mathrm{CuI}$. In the latter, packing of tetrahedral $\mathrm{Cu}^{+}$and $\mathrm{I}^{-}$centers produces either the cubic zinc blende or hexagonal wurtzite forms. Of course, the hexagonal channels in $\mathrm{CuSCN}$ networks, unlike those in $\mathrm{CuI}$, are distorted by the length of the thiocyanate ion.

The introduction of organic ligands has been shown to restrict inorganic network formation in CuSCN. Addition of monodentate "capping" ligands (L), such as aromatic amines, typically results in one of three common CuSCN motifs: chains (A), ladders (B), or hexagonal sheets (C), see Chart 1. Type A networks consist of isolated $(\mathrm{CuSCN})_{\infty}$ chains linked via $\mu_{2}-(\mathrm{N}, \mathrm{S})$-thiocyanate bridging, with the copper(I) coordination being completed either by pairs of ligand molecules (A) or single ligand molecules $\left(\mathrm{A}^{\prime}\right)$. Thus, copper centers are 4-coordinate in Type A, and 3-coordinate in Type A'. Type A polymers 
have been identified for $\mathrm{L}=2-\mathrm{MePy}(\mathrm{Py}=$ pyridine), 3-MePy, 4-MePy, 4-EtPy, 2,4-Me $2 \mathrm{Py}$, and quinoline $[3,4]$. Type A' polymers are known for the more hindered $\mathrm{L}=2,6-\mathrm{Me}_{2} \mathrm{Py}$ and 2,4,6-Me $3 \mathrm{Py}[3,4]$. 


\section{A, CuSCNL 2 ; A', CuSCNL}

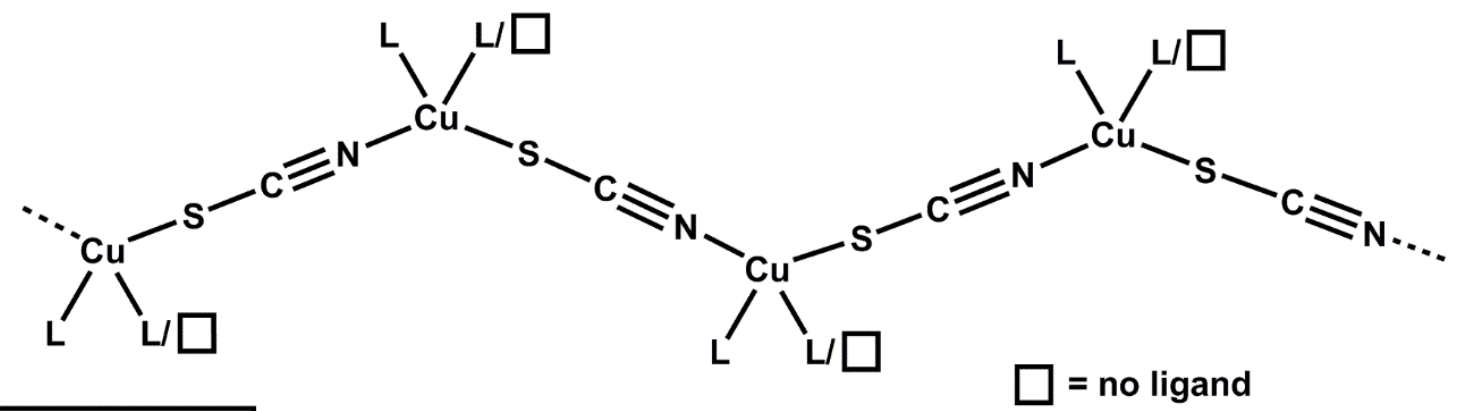

\section{B, CuSCNL}

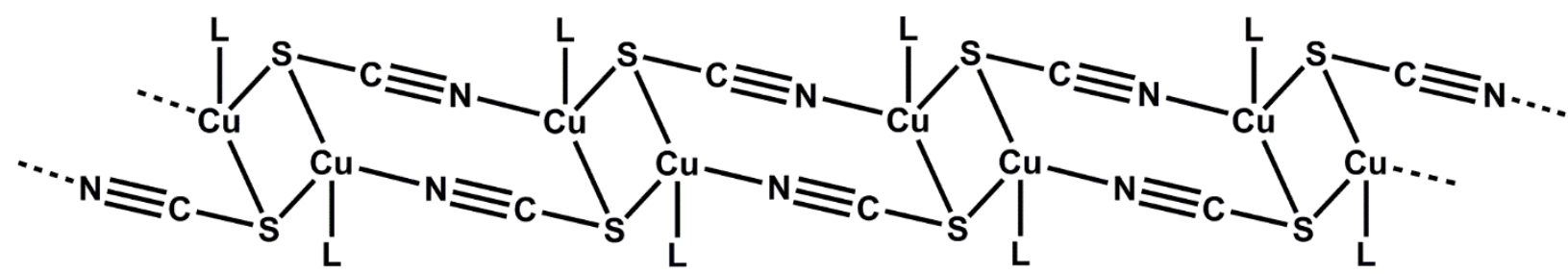

\section{C, CuSCNL}

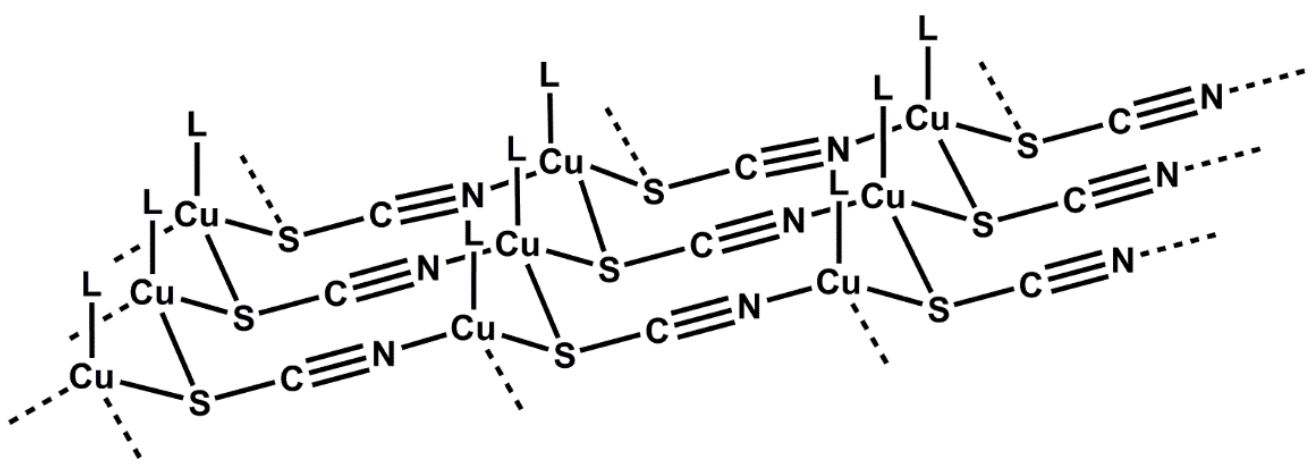

cis-fusion: square wave sheet

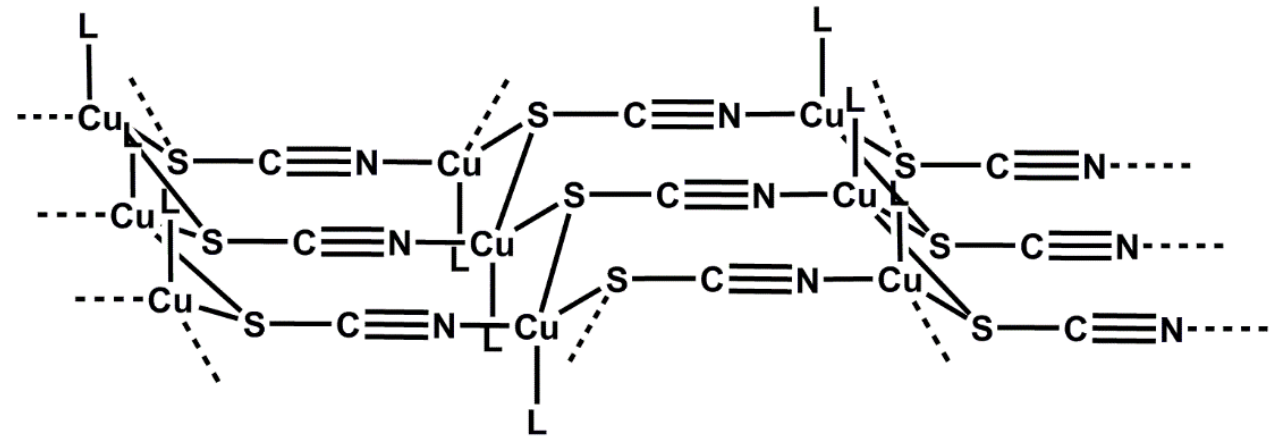

Chart 1. CuSCN Network Motifs. 
In the case of network types $\mathrm{B}$ and $\mathrm{C}$, additional coordination of $\mathrm{Cu}$ centers to thiocyanate sulfur produces $\mu_{3}-(\mathrm{N}, \mathrm{S}, \mathrm{S})$-thiocyanate bridging between $\mathrm{CuSCN}$ chains. For Type B complexes this results in the formation of $\left[\mathrm{Cu}_{2}(\mathrm{SCN})_{2}\right]_{\infty}$ ladders composed of alternating $\mathrm{Cu}_{2} \mathrm{~S}_{2}$ and $\mathrm{Cu}_{2}(\mathrm{SCN})_{2}$ rings. Type $\mathrm{B}$ ladders have been found for $\mathrm{L}=2-\mathrm{MePy}, 2-\mathrm{EtPy}$, and N-methylpiperidine [3, 4]. While Type B ladders can be envisioned as arising from linked pairs of Type $\mathrm{A}^{\prime}$ chains, Type $\mathrm{C}$ networks are likewise formed from series of type $\mathrm{A}^{\prime}$ chains crosslinked in two directions to form 2-D rippled sheets consisting of fused $\mathrm{Cu}_{3}(\mathrm{SCN})_{2} \mathrm{~S}$ macrocycles. This arrangement is tantamount to extraction of an atom layer from $\mathrm{CuSCN}$ and capping of that layer on one or both faces with L ligands. The elongated hexagonal rings fuse in either trans (chair-like) or cis (boat-like) fashion, yielding zigzag or square-wave cross-sections respectively (see Chart 1). Type $\mathrm{C}$ decorated sheets are recognized for $\mathrm{L}=3-\mathrm{ClPy}$ (trans), 3-BrPy (trans), and N-methylmorpholine (cis) [4].

The use of bridging ligands (LL) with CuSCN results in increased networking in these, and a few other, motifs. Crosslinking of chains by bridging ligands results in expansion of Type A chains into 2-D sheets having stoichiometry $(\mathrm{CuSCN})(\mathrm{LL})$. Type B ladders can be linked together to form 2-D sheets of stoichiometry $(\mathrm{CuSCN})_{2}(\mathrm{LL})$. Linking can occur in either of two fashions with adjacent ladders related either by mirror or inversion symmetry [5, 6]. Finally, crosslinking of Type C sheets by LL produces 3-D networks. As with the non-bridged sheets, both zigzag (chair) and square wave (boat) topologies are encountered. In some cases, more than one network type can be produced using a particular ligand.

When potentially bidentate pyrazine (Pyz, see Chart 2) ligands are used, a variety of networks are encountered. Known pyrazine networks with $\mathrm{CuSCN}$ include (1) 2-D sheets of crosslinked Type A chains, LL = Pyz, 2-MePyz [7, 8], (2) 2-D sheets of crosslinked Type B ladders, LL = 2-MePyz [5, 6], (3) 3-D crosslinked trans-fused Type C networks, LL = Pyz and 2,5-Me 2 Pyz $[9,10,11]$, and (4) a 3-D crosslinked cis-fused Type C network, LL = 2-Me-3-EtPyz [12]. Two additional bridging Pyz networks are based upon the simple rhomboid $\mathrm{Cu}_{2} \mathrm{~S}_{2}$ building unit. In both $(\mathrm{CuSCN})_{2}(3-\mathrm{IPyz})$ and $(\mathrm{CuSCN})_{2}(2,3-$ $\left.\mathrm{Me}_{2} \mathrm{Pyz}\right), \mathrm{Cu}_{2} \mathrm{~S}_{2}$ rings are linked together by both the SCN tails and the LL ligands. The resulting 3-D networks can be envisioned as being based upon Type B ladders in which the $\mathrm{Cu}_{2}(\mathrm{SCN})_{2}$ rings have been 
opened, and thus form links in orthogonal directions [13, 14]. Finally, two substituted Pyz ligands have been shown behave in non-bridging monodentate fashion, forming $(\mathrm{CuSCN})(2-\mathrm{NCPyz})_{2}$, a 1-D Type A chain (2-NCPyz bonds through a ring N) [5], and (CuSCN)(2-Me-3-EtPyz), a 1-D Type B ladder [12].

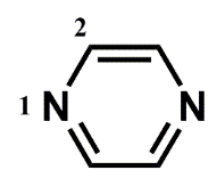

Pyrazine (Pyz)<smiles>c1ccc2nccnc2c1</smiles>

Quinoxaline (Qox)

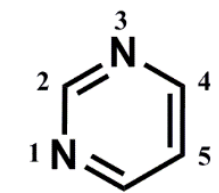

Pyrimidine (Pym)

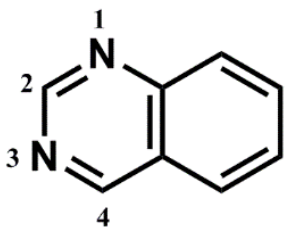

Quinazoline (Qnz)

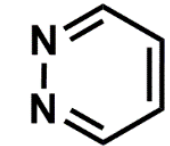

Pyridazine (Pdz)

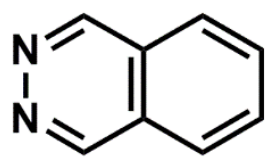

Phthalazine (Ptz)

Chart 2. Ligands (with numbering where needed).

Pyrimidine (Pym) ligands are disadvantaged as bridges by their $120^{\circ}$ bite angle, creating difficulties for the crosslinking of sheets. As a result many Pym complexes are monodentate. These include $(\mathrm{CuSCN})(4-\mathrm{HOPym})_{2}$, which is a Type A chain [5], and $(\mathrm{CuSCN})(4-\mathrm{MePym})$ and $(\mathrm{CuSCN})(5-$ BrPym), both of which are trans-fused Type $\mathrm{C}$ sheets $[5,8]$. Alternatively in the 3-D $(\mathrm{CuSCN})_{2}(\mathrm{Pym})$ network, bidentate Pym ligands bridge large $\mathrm{Cu}_{4}(\mathrm{SCN})_{2} \mathrm{~S}_{2}$ pores in a series of Type A chains that are crosslinked by $\cdots \mathrm{Cu}-\mathrm{S}-\mathrm{Cu}-\mathrm{S} \cdots$ chains $[15]$. The 3-D $(\mathrm{CuSCN})_{2}(4-\mathrm{MePym})$ network is altogether different, consisting of orthogonal sets of Type $\mathrm{C}$ sheets (both zigzag and square wave type) which are connected by not only through the LL ligand, but also via $\mathrm{Cu}_{3} \mathrm{~S}_{3}$, rings [5]. Pyridazine (Pdz) ligands have not been widely studied with CuSCN. Only the parent ligand complex is known. It fails to bridge, acting in monodentate fashion and forming $(\mathrm{CuSCN})(\mathrm{Pdz})$, a cis-fused Type $\mathrm{C}$ sheet [16].

Herein we present the synthesis and structure of five new CuSCN-aromatic diimine compounds containing $\mathrm{LL}=$ quinoxaline $(\mathrm{Qox})$, quinazoline $(\mathrm{Qnz})$, pthalazine $(\mathrm{Ptz})$, 2-aminopyrazine $\left(2-\mathrm{NH}_{2} \mathrm{Pyz}\right)$ and 2-methoxypyrazine (2-MeOPyz). The closely related Qox, Qnz and Ptz were found to show 
networking behavior with CuSCN that differed greatly from that of their single-ring analogs: Pyz, Pym, and Pdz, respectively.

\section{Experimental}

\subsection{Materials and Methods}

All reagents were purchased from Aldrich or Acros and used without purification, except for quinoxaline (Qox), which was sublimed before use. Commercial CuSCN (Aldrich) was shown by FTIR to consist solely of the $\alpha$-phase [17]. IR spectra were collected on a Shimadzu IRTracer-100 instrument using a diamond ATR probe (spectra shown in Supporting Information). Analyses for C, H, and N were carried out by Atlantic Microlabs, Norcross, GA. Atomic absorption analyses for $\mathrm{Cu}$ were carried out using a Perkin-Elmer AAnalyst 700 as previously described [18]. Thermogravimetric analyses (TGA) were conducted using a TA Instruments Q500 in the dynamic (variable temp.) mode with a maximum heating rate of $50{ }^{\circ} \mathrm{C} / \mathrm{min}$. to $800{ }^{\circ} \mathrm{C}$ under $50 \mathrm{~mL} / \mathrm{min} . \mathrm{N}_{2}$ flow.

\subsection{Syntheses}

$(\mathrm{CuSCN})_{2}(\mathrm{Qox})$, 1. CuSCN (121 mg, $\left.1.00 \mathrm{mmol}\right)$ was suspended in $20 \mathrm{~mL}$ deionized water containing $146 \mathrm{mg}(1.5 \mathrm{mmol}) \mathrm{KSCN}$ and $0.5 \mathrm{~mL} 17 \mathrm{M} \mathrm{NH}_{3}(8.5 \mathrm{mmol})$ under Ar purge. Qox (70 mg, $0.54 \mathrm{mmol}$ ) was added to the suspension, which quickly took on a red-orange color. The suspension was refluxed for $72 \mathrm{~h}$. The red solid product was collected via filtration, washed with deionized water, and dried under vacuum (123 mg, 66\%). IR ( $\left.\mathrm{cm}^{-1}\right)$ : 2086 (strong), 1500, 1362, 1207, 1049, 867, 764 (strong).

Anal. Calcd for $\mathrm{C}_{10} \mathrm{H}_{6} \mathrm{Cu}_{2} \mathrm{~N}_{4} \mathrm{~S}_{2}: \mathrm{Cu}, 34.03 ; \mathrm{C}, 32.17 ; \mathrm{H}, 1.62 ; \mathrm{N}, 15.00$. Found: $\mathrm{Cu}, 33.93 ; \mathrm{C}, 31.40 ; \mathrm{H}$, 1.66; N, 14.45. TGA calcd for CuSCN: $65.2 \%$. Found: $66.3 \%\left(140-190{ }^{\circ} \mathrm{C}\right)$.

$(\mathrm{CuSCN})(\mathrm{Qnz}), 2$. The procedure for 1 was followed using Qnz $(133 \mathrm{mg}, 1.02 \mathrm{mmol})$ in the place of Qox. A yellow solid was collected (145 mg, 57\%). IR ( $\left.\mathrm{cm}^{-1}\right)$ : 2113 (strong), 1616, 1574, 1489, 1373, 1211, 926, 791, 745 (strong), 633. Anal. Calcd for $\mathrm{C}_{9} \mathrm{H}_{6} \mathrm{Cu}_{1} \mathrm{~N}_{3} \mathrm{~S}_{1}$ : Cu, 25.24; C, 42.93; H, 2.40; N, 16.69. 
Found: $\mathrm{Cu}, 27.08 \mathrm{C}, 41.28 ; \mathrm{H}, 2.27$; N, 16.08. TGA calcd for CuSCN: 48.3\%. Found: 51.9\% (125-170 $\left.{ }^{\circ} \mathrm{C}\right)$.

$(\mathrm{CuSCN})_{2}(\mathrm{Ptz}), 3$. The procedure for 1 was follow using Ptz (70 mg, $\left.0.54 \mathrm{mmol}\right)$ in place of Qox. A yellow solid was collected (87 mg, 46\%). IR ( $\left.\mathrm{cm}^{-1}\right)$ : 2137 (strong, sharp), 1574, 1447, 1377, 1308, 1273, 1219, 914, 741 (strong). Anal. Calcd for $\mathrm{C}_{10} \mathrm{H}_{6} \mathrm{Cu}_{2} \mathrm{~N}_{4} \mathrm{~S}_{2}$ : Cu, 34.04; C, 32.17; H, 1.62; N, 15.00 . Found: 34.89 ; C, 31.33; H, 1.58; N, 14.51. TGA calcd for CuSCN: $65.2 \%$. Found: $66.6 \%\left(200-250{ }^{\circ} \mathrm{C}\right)$.

$(\mathrm{CuSCN})_{2}\left(2-\mathrm{NH}_{2} \mathrm{Pyz}\right), 4$. The procedure for 1 was follow using 2- $\mathrm{NH}_{2} \mathrm{Pyz}(65 \mathrm{mg}, 0.68 \mathrm{mmol})$ in place of Qox. A yellow solid was collected (106 mg, 63\%). IR ( $\left.\mathrm{cm}^{-1}\right): 3418,3317,2102$ (strong), 1616 (strong), 1593, 1528 (strong), 1435, 1215, 1029, 817, 768. Anal. Calcd for $\mathrm{C}_{6} \mathrm{H}_{5} \mathrm{Cu}_{2} \mathrm{~N}_{5} \mathrm{~S}_{2}$ : Cu 37.56; C, 21.30; H, 1.49; N, 20.70. Found: Cu, 36.32; C, 20.41; H, 1.38; N, 19.73. TGA calcd for CuSCN: 71.9\%. Found: $74.0 \%\left(115-220^{\circ} \mathrm{C}\right)$.

$(\mathrm{CuSCN})(2-\mathrm{MeOPyz})$, 5. CuSCN (100 mg, $0.82 \mathrm{mmol})$ was stirred in $500 \mu \mathrm{L}$ neat 2-MeOPyz (5.18 mmol) under Ar for $3 \mathrm{~d}$ at ambient temp. A yellow solid was collected by filtration, washed with ethyl ether, and dried under vacuum (154 mg, 81\%). IR ( $\left.\mathrm{cm}^{-1}\right)$ : 2123 (strong, sharp), 1587, 1529 (strong), 1471, 1438, 1398, 1311, 1284, 1195, 1145, 1060, 1014 (weak), 1004 (strong, sharp), 837, 759, 617. Anal. Calcd for $\mathrm{C}_{6} \mathrm{H}_{6} \mathrm{Cu}_{1} \mathrm{~N}_{3} \mathrm{O}_{1} \mathrm{~S}_{1}: \mathrm{Cu} 27.42 ; \mathrm{C} 31.10 ; \mathrm{H}, 2.61 ; \mathrm{N}, 18.13$. Found: $\mathrm{Cu}, 26.48 ; \mathrm{C}, 31.12 ; \mathrm{H}, 2.42 ; \mathrm{N}$, 17.95. TGA calcd for CuSCN: $52.5 \%$. Found: $53.9 \%\left(75-105{ }^{\circ} \mathrm{C}\right)$.

\subsection{Crystallizations}

Single crystals were grown from suspensions similar to those used in the bulk syntheses. Crystals of 1, 2, 3 and 4 were grown as follows: Deionized water $(35 \mathrm{~mL})$ containing CuSCN (121 mg, 1.00 mmol) and $\mathrm{KSCN}\left(97 \mathrm{mg}, 1.00 \mathrm{mmol}\right.$ ) was degassed using Ar. To this suspension, $\mathrm{NH}_{3}(17 \mathrm{M})$ was added drop-wise until most of the solid had dissolved (about $1 \mathrm{~mL}$ total). The ligand (66 mg Qox, $131 \mathrm{mg}$ Qnz, $66 \mathrm{mg}$ Ptz, or $54 \mathrm{mg}$ 2- $\mathrm{NH}_{2} \mathrm{Pyz}$ ) was then added and the solution was briefly stirred. It was then refluxed under Ar for $72 \mathrm{~h}$ without stirring. Crystals were observed on the surface of the aqueous layer within $24 \mathrm{~h}$, but were left to grow over another $48 \mathrm{~h}$. They were collected by filtration and washed with deionized water. 
Crystals of 5 were grown differently: CuSCN (100 mg, $0.82 \mathrm{mmol}$ ) was partially dissolved in 5 $\mathrm{mL} 1 \mathrm{MNH}_{3}$ (aq) under Ar. 2-MeOPyz (50 $\left.\mu \mathrm{L}, 0.52 \mathrm{mmol}\right)$ was dissolved in $3 \mathrm{~mL}$ EtOH and layered on top of the aqueous suspension and sealed in a $5 \mathrm{~mm}$ i.d. tube. Crystal growth became apparent after about two weeks when the solid emitted green upon exposure to UV light.

\subsection{X-ray data collection, structure solutions and refinements}

All X-ray measurements were made using graphite-monochromated $\mathrm{Cu} \mathrm{K} \alpha$ radiation on a BrukerAXS three-circle diffractometer, equipped with a SMART Apex II CCD detector. All data were collected at $100 \mathrm{~K}$. Initial space group determination was based on a matrix consisting of 120 frames. The data were corrected for Lorentz and polarization [19] effects and absorption using SADABS [20]. All structures were solved using direct methods or intrinsic phasing. Structure solution, refinement and the calculation of derived results were performed using the SHELXTL [21] package of software and ShelXle [22]. Non-hydrogen atoms were refined anisotropically. All hydrogen atoms were placed in theoretical positions.

\section{Results and Discussion}

\subsection{Synthesis and characterization}

The complexes of CuSCN with diimine ligands, LL = Qox, Qnz, Ptz, 2- $\mathrm{NH}_{2} \mathrm{Pyz}$, and 2-MeOPyz (1-5) were prepared and studied. An aqueous procedure was effective for the synthesis of four of the five complexes described herein. Thiocyanate ion and ammonia were used as mineralization and phasetransfer agents to partially solubilize $\mathrm{CuSCN}$ in aqueous medium. A prolonged three-day reflux was required to ensure complete conversion of $\mathrm{CuSCN}$ to the network product. TGA and powder X-ray diffraction analysis indicated the presence of residual CuSCN when shorter reflux times were used, or when no ammonia was added. Compounds 1-4 formed readily under these conditions, with the resulting suspensions taking on their characteristic color within seconds or minutes but complete conversion requiring several days. Additionally, the $\mathrm{H}_{2} \mathrm{O} / \mathrm{KSCN} / \mathrm{NH}_{3}$ reaction conditions enabled the convenient growth of single crystals for all four compounds when stirring of the mixture was omitted. The slow pace 
of the reaction due to the very limited aqueous solubility of CuSCN thus proved to be advantageous for crystal growth.

Pure samples of $\mathbf{5}$ could not be prepared under aqueous conditions, and were only accessible by stirring $\mathrm{CuSCN}$ in the neat ligand at room temperature. This method has previously been used to prepare monodentate ligand complexes of $\mathrm{CuSCN}$, yielding bulk powders when stirred and crystals when heated without stirring [4]. In order to grow crystals of this compound, $\mathrm{CuSCN}$ was fully dissolved in relatively concentrated aqueous ammonia and the ligand in ethanol solution layered on top of CuSCN solution [9].

All compounds were characterized via elemental analysis and found to be with acceptable range. Thermogravimetric analysis (TGA) was carried out on all complexes. The results shown in Figure S1 revealed loss of the diimine ligands at modest temperatures, commencing between 80 and $200{ }^{\circ} \mathrm{C}$. The thermal stability ranking of the complexes based on TGA results was: $\mathbf{5}<\mathbf{2}<\mathbf{1}<\mathbf{4}<\mathbf{3}$. Thus bidentate ligand binding in complexes $\mathbf{1}, \mathbf{3}$, and $\mathbf{4}$ imparted greater stability than monodentate binding seen in $\mathbf{2}$ and 5. No plateaus that might indicate the formation of metastable phases were observed during ligand loss. In all cases, CuSCN had formed by about $250^{\circ} \mathrm{C}$ and then decomposed near $400-450{ }^{\circ} \mathrm{C}$.

\subsection{Description of X-Ray Structures}

Crystal structures were solved for all complexes. The resulting structures generally fall into two of the recognized categories for CuSCN networks: bridged ladders (Type B, see Chart 1) and 2-D sheets (Type C). Crystallographic data are summarized in Table 1. Selected bond distances and angles for all complexes are given in Table S1. Thermal ellipsoid drawings of the asymmetric units for all compounds are found in the Supporting Information.

Compound 1 crystallized as long red needles that solved in centrosymmetric monoclinic space group $P 2_{1} / n$. Network diagrams are shown in Figure 1. The asymmetric unit consists of $(\mathrm{CuSCN})_{2}(\mathrm{Qox})$.

In 1, Type B CuSCN ladders are bridged by Qox ligands. The thiocyanate sulfur atoms bridge pairs of $\mathrm{Cu}$ atoms to form alternating rhomboid cyclic $\mathrm{Cu}_{2} \mathrm{~S}_{2}$ and $\mathrm{Cu}_{2}(\mathrm{SCN})_{2}$ dimers. The gross structure of $\mathbf{1}$ bears much resemblance to $(\mathrm{CuI})_{2}$ Qox [18], with the SCN anion acting as the $\mu_{3}$ bridging ligand in place of 
iodide. Copper atoms in 1 show distorted tetrahedral $\mathrm{S}_{2} \mathrm{~N}_{2}$ coordination environments: 100.56(8)$128.49(8)^{\circ}$. As with all such complexes, $\mathrm{Cu}-\mathrm{NCS}$ is significantly shorter than $\mathrm{Cu}-\mathrm{N}_{\text {aromatic }}(1.975(3)$ and 1.983(3) $\AA$ vs. 2.019(3) and 2.032(3) $\AA$ ). The CuSCN ladders propagate along the $a$-axis. The ladders repeat along the $b$-axis as they are bridged by Qox. Pairs of CuSCN chains are linked in an anti-parallel fashion to form the ladder motif, with Qox ligands forming the steps in a square wave pattern in the sheets when viewed from the side. The Qox groups are sufficiently displaced from one another along rows such that the nearest centroid $\cdots$ centroid distance is approximately $4.14 \AA$, ruling out $\pi$-stacking. A very close $\mathrm{Cu}^{\cdots} \mathrm{Cu}$ interaction of $2.7305(6) \AA$ is noted across the $\mathrm{Cu}_{2} \mathrm{~S}_{2}$ rhombus. This distance falls within the van der Waals radius sum for copper $(2.8 \AA)$ and is correlated with relatively acute angles at S of 67.79(3) and $70.17(3)^{\circ}$. Similar behavior is noted for the $\mathrm{Cu}_{2} \mathrm{I}_{2}$ rhombs in $(\mathrm{CuI})_{2}$ Qox [18], and is also apparent in other CuSCN ladder networks. [5, 6, 23].

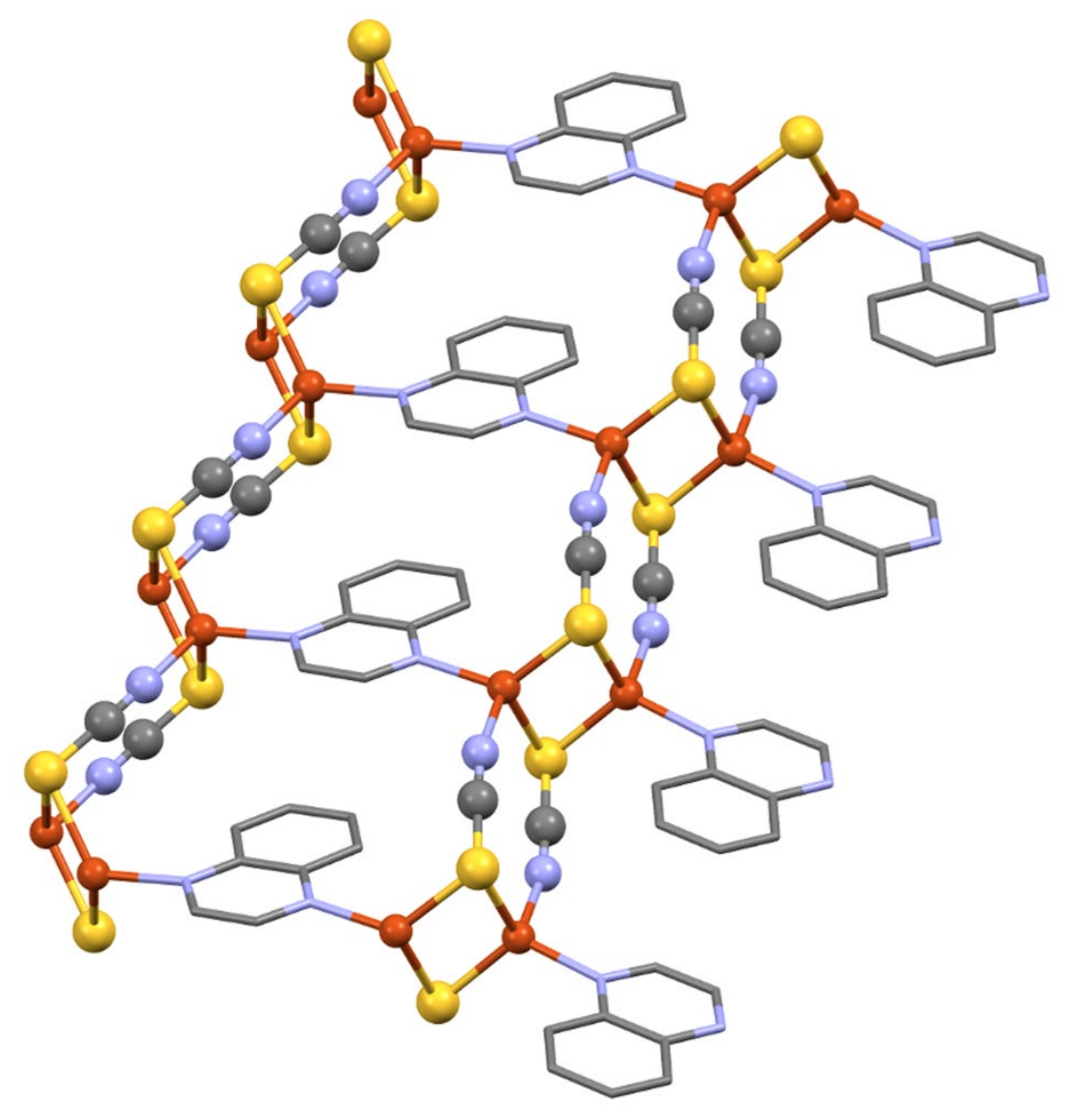




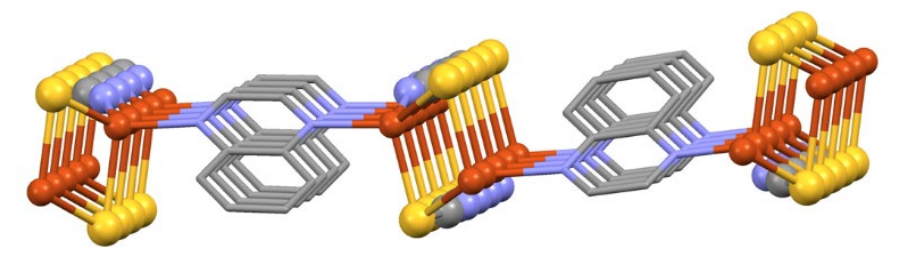

Figure 1. Network formation for 1. CuSCN atoms shown as ball and stick, and Qox atoms as wireframe. Hydrogen atoms are omitted. Top: view along $c$-axis, bottom: view along $a$-axis. Color scheme for all Xray figures: orange $=\mathrm{Cu}$, yellow $=\mathrm{S}$, grey $=\mathrm{C}$, blue $=\mathrm{N}$, red $=\mathrm{O}$. Selected bond lengths $(\AA)$ and angles $\left(^{\circ}\right): \mathrm{Cu}-\mathrm{SCN}=2.3185(9), 2.2788(9), 2.4641(9), 2.5641(9), \mathrm{Cu}-\mathrm{NCS}=1.975(3), 1.983(3), \mathrm{Cu}-\mathrm{N}_{\text {arom }}=$ 2.019(3), 2.032(3), $\mathrm{Cu} \cdots \mathrm{Cu}=2.7305(6), \mathrm{Cu}-\mathrm{S}-\mathrm{C}=93.99(11), 106.04(11), \mathrm{C}-\mathrm{N}-\mathrm{Cu}=161.7(3), 162.9(3)$, $\mathrm{Cu}-\mathrm{S}-\mathrm{Cu}=67.79(3), 70.17(3)$.

The 1:1 CuSCN:Qnz compound 2 crystallized as small yellow plates. The structure was solved in the non-centrosymmetric monoclinic space group $C c$. A network diagram are shown in Figure 2 . As has previously been observed for CuSCN complexes of Pym ligands, this first-reported Qnz complex contains only monodentate ligands. It forms a trans-fused Type C network (see Chart 1). Thus, the gross structure of 2 bears much resemblance to the parent $\mathrm{CuSCN}$ networks, essentially comprising a series of exfoliated sheets consisting of elongated, fused $\mathrm{Cu}_{3}(\mathrm{SCN})_{2} \mathrm{~S}$ rings. Zigzag $(\mathrm{CuS})_{\infty}$ chains run parallel to the $b$-axis and the 2-D sheets run parallel to the crystallographic $b, c$ plane. The 4-coordinate $\mathrm{Cu}$ atoms have a $\mathrm{S}_{2} \mathrm{~N}_{2}$ coordination sphere, in which one of the nitrogen atoms is associated with the monodentate Qnz ligand. Angles around $\mathrm{Cu}$ are very close to tetrahedral: 106.30(19)-112.4(3) . Each copper atom is capped by a monodentate Qnz ligand, all of which are located on a single sheet face. The Qnz ligands along individual zigzag $(\mathrm{CuS})_{\infty}$ chains are canted in identical positions and are $\pi$-stacked with identical centroid-centroid distances of $3.764 \AA$ between adjacent carbocyclic rings and between adjacent heterocyclic rings. The cant angle of the Qnz rings alternates between adjacent $(\mathrm{CuS})_{\infty}$ chains, with an inter-planar angle of $44.62^{\circ}$. All the sheets are identically aligned, such that the carbocyclic Qnz rings lie relatively close to the undecorated side of the adjacent sheet. This results in several close interactions between ring hydrogens 
and thiocyanate: $\mathrm{H} 6 \cdots \mathrm{C} 1=3.025 \AA, \mathrm{H} 6 \cdots \mathrm{S} 1=2.864 \AA, \mathrm{H} 5 \cdots \mathrm{N} 1=3.154 \AA, \mathrm{H} 5 \cdots \mathrm{C} 1=3.337 \AA$. In the current structure, Qnz coordinates only through the 3-position nitrogen atom (see Chart 2). This allows the long axis of the ligand to point outward from the $\mathrm{CuSCN}$ sheet.

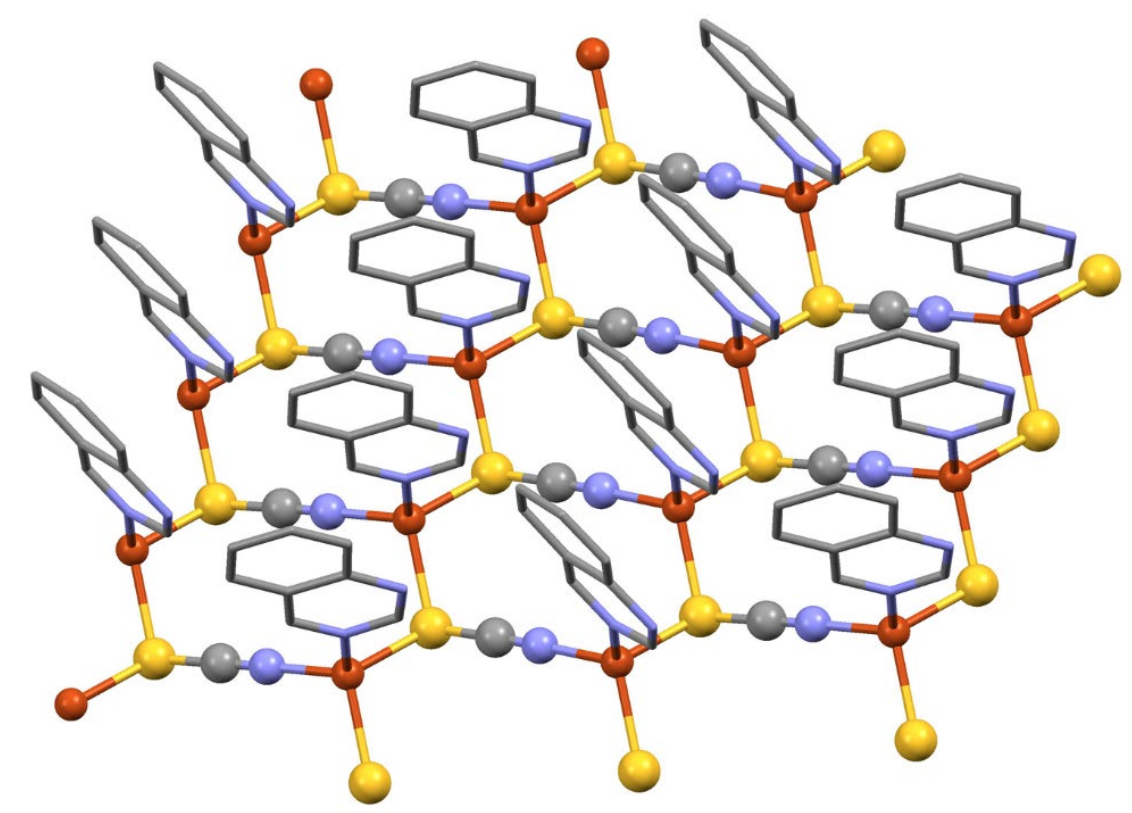

Figure 2. Network formation in 2, viewed down the $a, b$-axis bisector. CuSCN atoms shown as ball and stick, and Qnz atoms as wireframe. Hydrogen atoms are omitted. Selected bond lengths $(\AA)$ and angles $\left(^{\circ}\right): \mathrm{Cu}-\mathrm{SCN}=2.345(2), 2.349(2), \mathrm{Cu}-\mathrm{NCS}=1.953(8), \mathrm{Cu}-\mathrm{N}_{\text {arom }}=2.057(7), \mathrm{Cu}-\mathrm{S}-\mathrm{C}=104.8(3)$, 108.3(3), $\mathrm{C}-\mathrm{N}-\mathrm{Cu}=177.5(7), \mathrm{Cu}-\mathrm{S}-\mathrm{Cu}=106.60(8)$.

Compound 3 crystallized as yellow plates, solving in the centrosymmetric orthorhombic space group Pbcn. Network diagrams are shown in Figure 3. As was the case with 2, compound 3 formed Type C 2-D CuSCN sheets consisting of 10 -membered $\mathrm{Cu}_{3}(\mathrm{SCN})_{2} \mathrm{~S}$ rings. However, rather than having LL ligands either monodentate or bridging between sheets, the Ptz ligands bridge pairs of $\mathrm{Cu}$ atoms within single sheets. This produces five-membered $\mathrm{Cu}_{2} \mathrm{~N}_{2} \mathrm{~S}$ rings that project obliquely from the faces of the sheets, an effect we describe as ligand "stapling". The stapling effect of the Ptz ligands between pairs copper atoms draws these pairs relatively close together. Thus, the stapled $\mathrm{Cu} \cdots \mathrm{Cu}=3.042 \AA$, while the non-stapled $\mathrm{Cu} \cdots \mathrm{Cu}=3.889 \AA$. Furthermore, the stapled $\mathrm{Cu}-\mathrm{S}-\mathrm{Cu}$ bond angle is $77.083(16)^{\circ}$, while the 
non-stapled $\mathrm{Cu}-\mathrm{S}-\mathrm{Cu}$ angle is $109.84(2)^{\circ}$. The stapling strain is also reflected in large deviations from ideal tetrahedral angles around $\mathrm{Cu}$, ranging from $93.58(4)^{\circ}$ to $134.53(7)^{\circ}$. Stapling also introduces significant strain into the Type C 10-membered rings, half of which are chairs, while the other half are twist boats, the two forms alternating along edge-sharing rows. This type of bridging causes the sheet to become significantly distorted compared to other known Type C structures, such as $\mathbf{2}$ or $\mathbf{5}$. The CuSCN chains, which propagate roughly parallel to the $b$-axis are modestly distorted. However, the CuS chains, which propagate parallel the $a$-axis, are highly distorted by the stapling effect of the Ptz ligands.
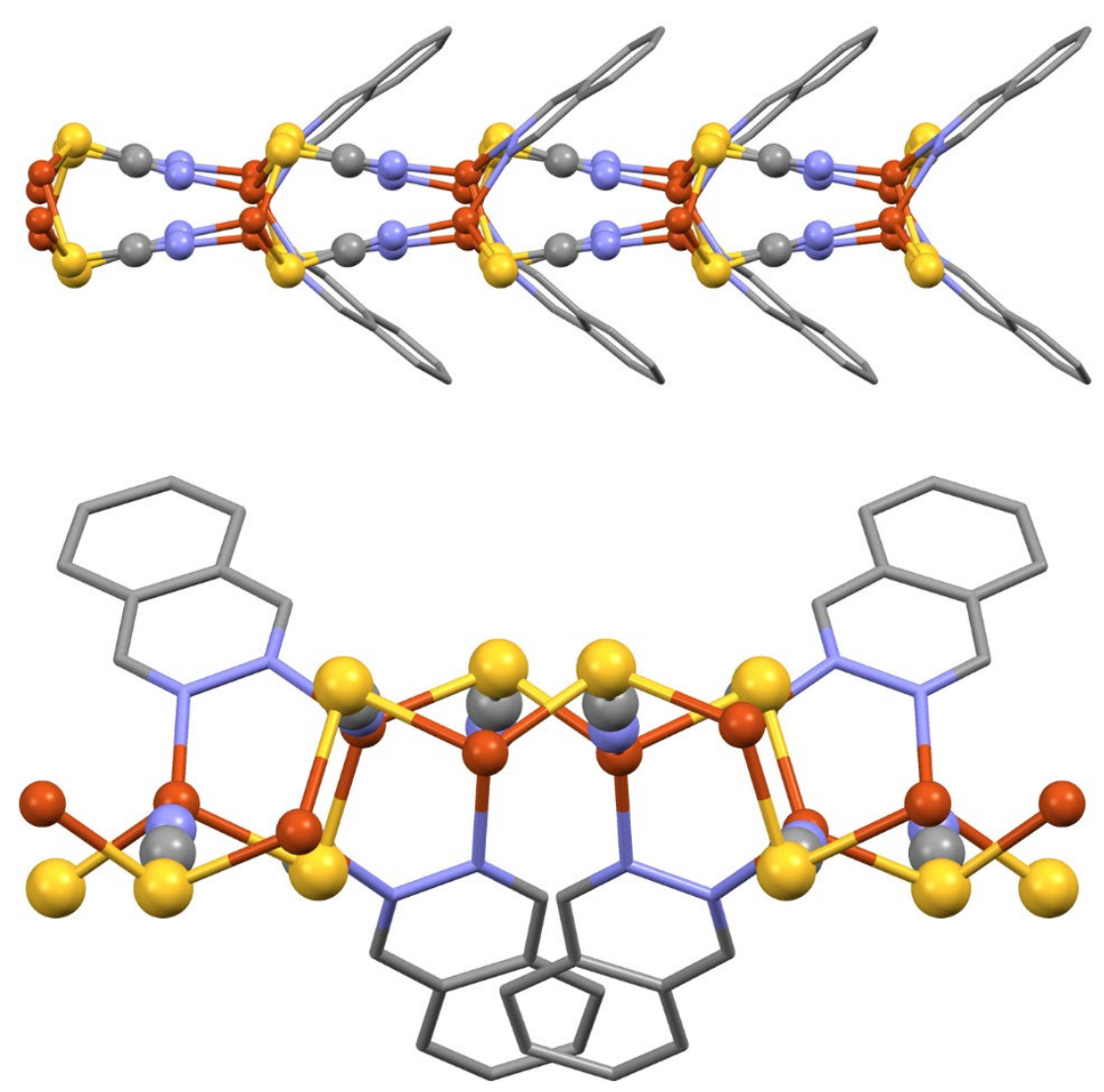

Figure 3. Network formation in 3. CuSCN atoms shown as ball and stick, and Ptz atoms as wireframe. Hydrogen atoms are omitted. Top: view along $c$-axis, center: view along $a$-axis, bottom: view along $b$ axis. Selected bond lengths $(\AA)$ and angles $\left(^{\circ}\right)$ : $\mathrm{Cu}-\mathrm{SCN}=2.3641(5), 2.3883(5), 2.3994(5), 2.4814(5)$, $\mathrm{Cu}-\mathrm{NCS}=1.9035(18), 1.9272(17), \mathrm{Cu}-\mathrm{N}_{\text {arom }}=2.0038(16), 2.0839(16), \mathrm{Cu}{ }^{\cdots} \mathrm{Cu}=3.0417(4), \mathrm{Cu}-\mathrm{S}-\mathrm{C}=$ 
100.11(7), 100.69(6), 100.70(7), 102.25(7), C-N-Cu = 173.56(16), 177.13(16), $\mathrm{Cu}-\mathrm{S}-\mathrm{Cu}=77.083(16)$, 109.84(2).

The Ptz ligands alternate between faces of the sheet, producing a roughly square wave pattern in which each wave contains a $\mathrm{Cu}-\mathrm{S}-\mathrm{Cu}-\mathrm{S}$ unit. There is no evidence of $\pi$-stacking between Ptz ligands or interactions between the sheets. There are two orientations of the Ptz group, their ring planes lying at angles of $15.9^{\circ}$ to one another. The Ptz planes are found to lie at angles of $50.5^{\circ}$ and $51.0^{\circ}$ with respect to the CuSCN sheet plane (calculated using the nearly-parallel CuSCN units). The bridging behavior of Ptz is noteworthy when compared with its single-ring analog $\mathrm{Pdz}[14]$. The known network $(\mathrm{CuSCN})(\mathrm{Pdz})$ is composed of cis-fused Type C sheets with Pdz acting as a monodentate capping ligand, as is seen herein for Qnz in the trans-fused Type C complex 2. In contrast to 3, neither of the monodentate Pdz or Qnz structures show meaningful evidence of strain in the sheet arrangements, bond lengths or bond angles.

Compound 4 crystallized as orange blocks that solved in the centrosymmetric triclinic space group $P-1$. Network diagrams for 4 are shown in Figure 4 . The crystallographically independent unit consists of $(\mathrm{CuSCN})\left(2-\mathrm{NH}_{2} \mathrm{Pyz}\right)_{0.5}$. Because the 2- $\mathrm{NH}_{2} \mathrm{Pyz}$ ligand in 4 is centered on an inversion center, the $\mathrm{NH}_{2}$ substituent is disordered over two positions (see Supporting Information). As was seen for 1, the networking in compound $\mathbf{4}$ is composed of a series of crosslinked Type B ladders, which propagate parallel to the $a$-axis. Linking of the ladders by $2-\mathrm{NH}_{2} \mathrm{Pyz}$ occurs in a direction parallel to the $a, c$-axis bisector. Unlike compound $\mathbf{1}$, the $\mathrm{Cu} \cdots \mathrm{Cu}$ separation of 3.0032(10) $\AA$ in the $\mathrm{Cu}_{2} \mathrm{~S}_{2}$ dimers is too large to be considered bonding. Correspondingly, the rhomboid dimer $\mathrm{Cu}-\mathrm{S}-\mathrm{Cu}$ angle of $72.89(2)^{\circ}$ was larger than those seen in $\mathbf{1}$. Viewed from the side, the sheets in $\mathbf{4}$ show a zigzag pattern. The $\mathrm{Cu}_{2} \mathrm{~S}_{2}$ units lie in like orientation and are bridged by LL units across oppositely oriented $\mathrm{Cu}$ centers. In $\mathbf{1}$, by way of contrast, the $\mathrm{Cu}_{2} \mathrm{~S}_{2}$ units lie alternating orientations, creating a square wave pattern (see Figure 1). 

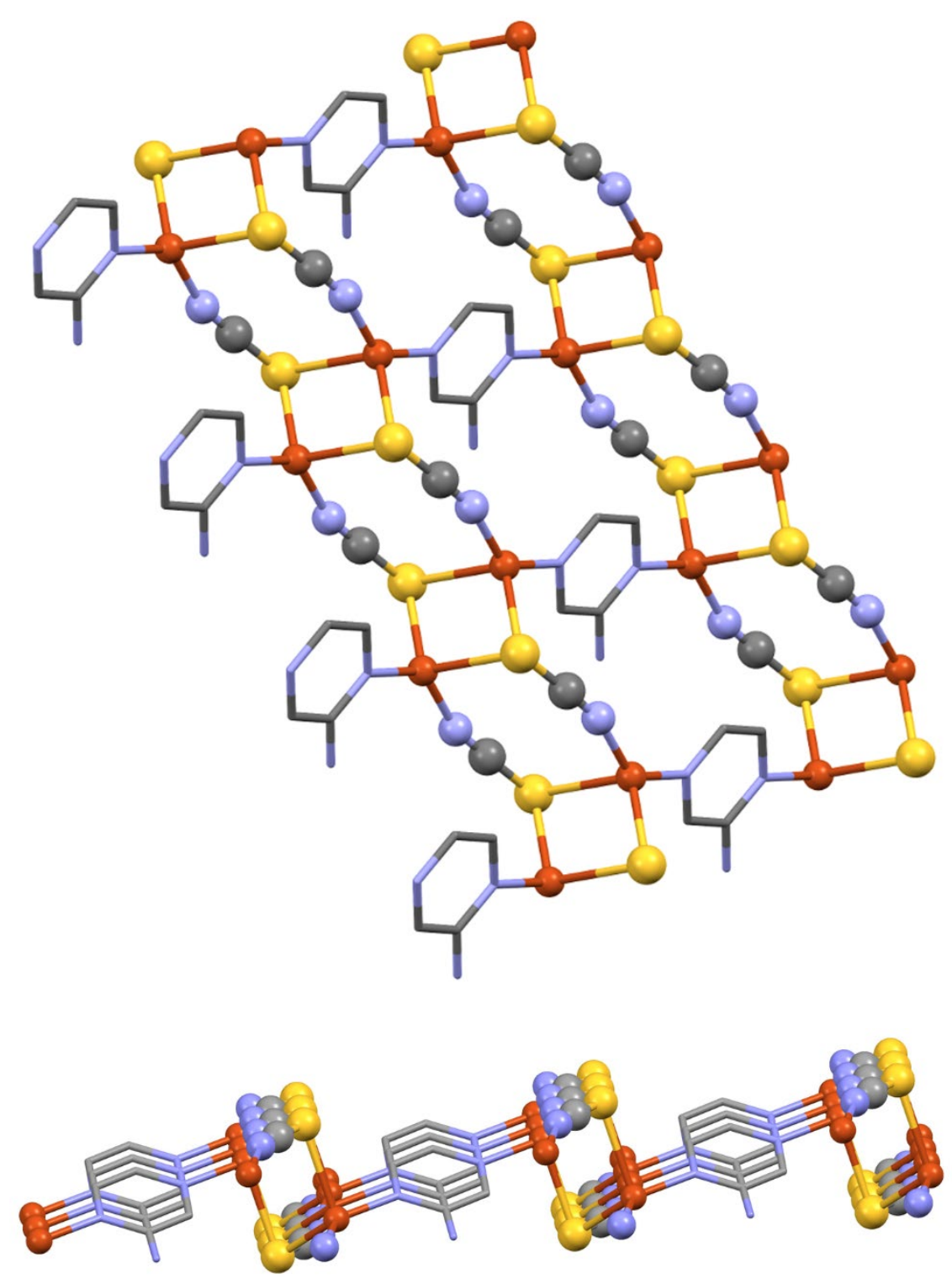

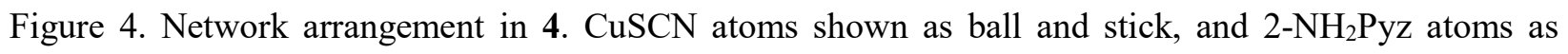
wireframe. Hydrogen atoms are omitted. Top: view along $b$-axis, bottom: view along $a$-axis. Ligand disorder has been omitted. Selected bond lengths $(\AA)$ and angles $\left(^{\circ}\right): \mathrm{Cu}-\mathrm{SCN}=2.3572(11), 2.6803(13)$, $\mathrm{Cu}-\mathrm{NCS}=1.921(4), \mathrm{Cu}-\mathrm{N}_{\text {arom }}=1.997(4), \mathrm{Cu}^{\cdots} \mathrm{Cu}=3.0031(16), \mathrm{Cu}-\mathrm{S}-\mathrm{C}=96.78(13), 102.04(15), \mathrm{C}-\mathrm{N}-$ $\mathrm{Cu}=163.8(3), \mathrm{Cu}-\mathrm{S}-\mathrm{Cu}=72.87(4)$.

Compound 5 crystallized as small colorless blades, solving in the centrosymmetric orthorhombic space group Pnnm. A network diagram is shown in Figure 5. The networking structure consists of Type C 
sheets with cis ring fusions. As was the case with Qnz in 2, 2-MeOPyz acts as a monodentate ligand. However, in 5, 2-MeOPyz ligands are present on both faces of the CuSCN sheet, similar to monodentate complexes $(\mathrm{CuSCN})(2-\mathrm{Me}-3-\mathrm{EtPyz})$ and $(\mathrm{CuSCN})(\mathrm{Pdz})[10,14]$. The cis-fused boat conformation of the $\mathrm{CuSCN}$ rings allows for ligand decoration on both faces of the sheets, which in the case of $\mathbf{5}$ run parallel to the $a, c$ plane. All CuSCN chains lie directly on a mirror plane, but for the 2-MeOPyz ligand only atoms $\mathrm{N} 1$ (coordinated to $\mathrm{Cu}$ ) and $\mathrm{C} 3$ (meta to $\mathrm{N} 1$ ) lie directly on a mirror plane. The remaining atoms $\mathrm{C} 1, \mathrm{C} 2$, C4, N2, O1, and C5 are slightly displaced to either side of a mirror plane, resulting in two-site disorder (see Supporting Information). There is no evidence of interactions between the sheets, or of $\pi$-stacking in the structure.

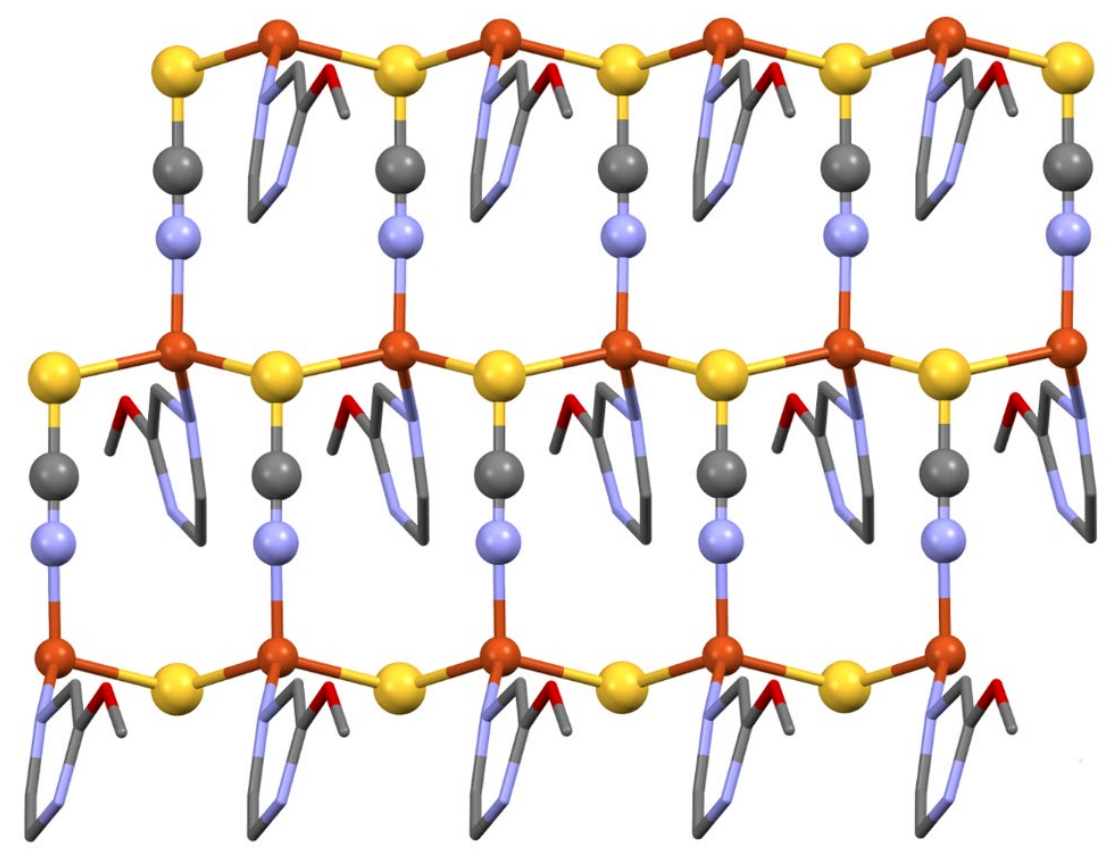

Figure 5: Network formation in $\mathbf{5}$, viewed down the $c$-axis. $\mathrm{CuSCN}$ atoms shown as ball and stick, and 2MeOPyz atoms as wireframe. Hydrogen atoms are omitted. Disordered 2-MeOPyz positions have been omitted. Selected bond lengths $(\AA)$ and angles $\left({ }^{\circ}\right): \mathrm{Cu}-\mathrm{SCN}=2.3513(5), \mathrm{Cu}-\mathrm{NCS}=1.944(3), \mathrm{Cu}-\mathrm{N}_{\text {arom }}=$ 2.041(3), $\mathrm{Cu}-\mathrm{S}-\mathrm{C}=102.69(6), \mathrm{C}-\mathrm{N}-\mathrm{Cu}=170.0(2), \mathrm{Cu}-\mathrm{S}-\mathrm{Cu}=108.55(3)$.

\section{Conclusions}


We have reported the synthesis of five new $\mathrm{CuSCN}$-aromatic diimine networks. Compounds $\mathbf{1}-\mathbf{4}$ were formed via reflux in dilute aqueous ammonia, while $\mathbf{5}$ was prepared by reacting CuSCN directly in the neat ligand. The diimines (LL) Qnz and 2-MeOPyz acted exclusively as monodentate capping ligands, producing 1:1 (CuSCN)(LL) stoichiometry in $\mathbf{2}$ and 5, respectively. Diimines Qox, Ptz and 2- $\mathrm{NH}_{2} \mathrm{Pyz}$ acted as $\mu_{2}$-bridging ligands, and produced $(\mathrm{CuSCN})_{2}(\mathrm{LL})$ networks $\mathbf{1}, \mathbf{3}$, and $\mathbf{4}$. Networks based on $\mathrm{CuSCN}$ ladders (1 and $\mathbf{4})$ and hexagonal sheets of fused $\mathrm{Cu}_{3}(\mathrm{SCN})_{2} \mathrm{~S}$ rings $(\mathbf{2}, \mathbf{3}$, and $\mathbf{5})$ were observed. In the ladder networks $\mathrm{Cu} \cdots \mathrm{Cu}$ distances within the $\mathrm{Cu}_{2} \mathrm{~S}_{2}$ rhombs were found lie near the van der Waals sum, representing either potentially bonding (1) or non-bonding interaction (4). Hexagonal sheet networks $\mathbf{2}$ and $\mathbf{5}$ exemplify trans-fusion of chair rings leading to zigzag rippled sheets and cis-fusion of boat rings leading to square wave rippled sheets, respectively. Of particular note is the intra-sheet bridging behavior exhibited by Ptz in 3. This "stapling" of sheets provides a contrast to crosslinking. It also introduces significant ring strain into the network, leading to buckled sheets of trans-fused alternating chair and twist boat rings. This stapling behavior stands in contrast to the known monodentate $(\mathrm{CuSCN})(\mathrm{Pdz})$ complex, and appears to be unprecedented.

Acknowledgement. We are indebted to NSF (CHE-0443345) and the College of William and Mary for the purchase of the X-ray equipment.

Appendix A. Supplementary data: CCDC 1460757-1460761 contains the supplementary crystallographic data for 1-5. These data can be obtained free of charge via http://www.ccdc.cam.ac.uk/conts/retrieving.html, or from the Cambridge Crystallographic Data Centre, 12 Union Road, Cambridge CB2 1EZ, UK; fax: (+44) 1223-336-033; or e-mail: deposit@ccdc.cam.ac.uk.

Supplementary data associated with this article can be found, in the online version.

\section{References:}


[1]: (a) R. Q. Snurr, J. T. Hupp, S. T. Nguyen. AIChE J. 50 (2004) 1090. (b) M. Hirscher, B. Panella, Scr. Mater. 56 (2007) 809. (c) K. Ding, L. Wang, L. Shi, Pure Appl. Chem. 79 (2007) 1531. (d) N. Sakai, S. Matile. Angew. Chem., Int. Ed. 47 (2008) 9603. (e) M. Kurmoo, Chem. Soc. Rev. 38 (2009) 1353.

[2] (a) M. Kabesova, M. Dunaj-Jurco, M. Serator, J. Gazo. Inorg. Chim. Acta, 17 (1976) 161. (b) D. L. Smith, V. I. Saunders. Acta Crystallogr., Sect. B 37 (1981) 1807. (c) D. L. Smith, V. I. Saunders. Acta Crystallogr. Sect. B 38 (1982) 907.

[3] P. C. Healy, C. Pakawatchai, R. I. Papasergio, V. A. Patrick, A. H. White. Inorg. Chem. 23 (1984) 3769.

[4] K. M. Miller, S. M. McCullough, E. A. Lepekhina, I. J. Thibau, R. D. Pike. Inorg. Chem. 50 (2011) 7239.

[5] O. Teichert, W. S. Sheldrick, Z. Anorg. Allg. Chem. 626 (2000) 2196.

[6] L. Li, R. Yuan, L. Liu, Z. Ren, A. Zheng, H. Cheng, H. Li, J. Lang. Cryst. Growth Des. 10 (2010) 1929.

[7] M. A. S. Goher, F. A. Mautner. Polyhedron 18 (1999) 1805.

[8] O. Teichert, W. S. Sheldrick. Z. Anorg. Allg. Chem. 625 (1999) 1860.

[9] A. J. Blake, N. R. Champness, M. Crew, L. R. Hanton, S. Parsons, M. Schroder. J. Chem. Soc., Dalton Trans. (1998) 1533.

[10] A. J. Blake, N. R. Brooks, N. R. Champness, M. Crew, L. R. Hanton, P. Hubberstey, S. Parsons, M. Schroder. J. Chem. Soc., Dalton Trans. (1999) 2813.

[11] T. Otieno, J. R. Blanton, K. J. Lanham, S. Parkin, J. Chem. Cryst. 33 (2003) 335.

[12] C. Näther, I. Jeß, P. Kowallik. Z. Anorg. Allg. Chem. 629 (2003) 2144.

[13] C. Näther, M. Wriedt, I. Jeß. Acta Crystallogr., Sect. E 61 (2005) m329.

[14] C. Näther, J. Greve, I. Jeß, C. Wickleder. Solid State Sci. 5 (2003) 1167.

[15] S. A. Barnett, A. J. Blake, N. R. Champness, C. Wilson. CrystEngComm, 2 (2000) 36.

[16] C. Näther, I. Jeß, Acta Crysallogr., Sect. C 60 (2004) m153.

[17] G. A. Bowmaker, J. V. Hanna. Z. Naturforsch. B 64 (2009) 1478. 
[18] P. M. Graham, R. D. Pike. Inorg. Chem. 39 (2000) 5121.

[19] SAINT PLUS: Bruker Analytical X-ray Systems: Madison, WI, 2001.

[20] SADABS: Bruker Analytical X-ray Systems: Madison, WI, 2001.

[21] G. M. Sheldrick, Acta Crystallogr., Sect. A. 64 (2008) 112.

[22] C. B. Hubschle, G. M. Sheldrick, B. Dittick. J. Appl. Cryst. 44 (2011) 1281.

[23] (a) Q. Wang, G. Guo, T. C. W. Mak. Chem. Commun. (1999) 1849. (b) Z. Hao, X. Zhang. Cryst. Growth Des. 7 (2007) 64. (c) R. J. Trovitch, R. S. Rarig, J. A. Zubieta, R. L. LaDuca, Acta Crystallogr., Sect. E 63 (2007) m339. (d) C. Näther, M. Wriedt. Dalton Trans. 46 (2009) 10125. (e) R. Peng, D. Li, T. Wu, X. Zhou, S. W. Ng. Inorg. Chem.45 (2006) 4035. (f) S. Liang, M. Li, M. Shao, X. He. J. Mol. Struc. 875 (2008) 17. (g) W. R. Knapp, J. G. Thomas, D. P. Martin, M. A. Braverman, R. J. Trovitch, R. L. LaDuca. Z. Anorg. Allg. Chem. 875 (2007) 575. 
Table 1. Crystal and Structure Refinement Data.

\begin{tabular}{|c|c|c|c|}
\hline complex & 1 & 2 & 3 \\
\hline CCDC deposit no. & 1460758 & 1460757 & 1460759 \\
\hline color and habit & orange prism & yellow plate & yellow block \\
\hline size, $\mathrm{mm}$ & $0.39 \times 0.10 \times 0.07$ & $0.18 \times 0.12 \times 0.05$ & $0.22 \times 0.17 \times 0.12$ \\
\hline formula & $\mathrm{C}_{10} \mathrm{H}_{6} \mathrm{Cu}_{2} \mathrm{~N}_{4} \mathrm{~S}_{2}$ & $\mathrm{C}_{9} \mathrm{H}_{6} \mathrm{CuN}_{3} \mathrm{~S}$ & $\mathrm{C}_{10} \mathrm{H}_{6} \mathrm{Cu}_{2} \mathrm{~N}_{4} \mathrm{~S}_{2}$ \\
\hline formula weight & 373.39 & 251.77 & 373.39 \\
\hline space group & $P 2_{1} / n(\# 14)$ & Cc $(\# 9)$ & $P b c a(\# 61)$ \\
\hline$a, \AA$ & $5.86660(10)$ & $21.6629(4)$ & $13.3325(3)$ \\
\hline$b, \AA$ & $17.5548(4)$ & $3.76380(10)$ & $10.8446(2)$ \\
\hline$c, \AA$ & $11.7576(3)$ & $11.2315(2)$ & $16.6635(3)$ \\
\hline$\alpha, \operatorname{deg}$ & 90 & 90 & 90 \\
\hline$\beta, \operatorname{deg}$ & $97.8520(10)$ & $101.4430(10)$ & 90 \\
\hline$\gamma, \operatorname{deg}$ & 90 & 90 & 90 \\
\hline volume, $\AA^{3}$ & $1199.53(5)$ & $2118.51(6)$ & $3837.12(16)$ \\
\hline Z & 4 & 4 & 8 \\
\hline$\rho_{\text {calc }}, \mathrm{g} \mathrm{cm}^{-3}$ & 2.068 & 1.863 & 2.059 \\
\hline $\mathrm{F}_{000}$ & 736 & 504 & 1472 \\
\hline$\mu(\mathrm{Cu} \mathrm{K} \alpha), \mathrm{mm}^{-1}$ & 2.068 & 1.863 & 2.059 \\
\hline temperature, $\mathrm{K}$ & $100(2)$ & $100(2)$ & $100(2)$ \\
\hline residuals: ${ }^{\mathrm{a}} \mathrm{R} ; \mathrm{R}_{\mathrm{w}}$ & $0.0330 ; 0.0843$ & $0.0432 ; 0.1328$ & $0.0201 ; 0.0577$ \\
\hline goodness of fit & 1.049 & 1.091 & 1.055 \\
\hline Flack & - & $0.03(4)$ & - \\
\hline
\end{tabular}

${ }^{\mathrm{a}} \mathrm{R}=R_{1}=\Sigma|| F_{o}|-| F_{c}|| / \Sigma\left|F_{o}\right|$ for observed data only. $\mathrm{R}_{\mathrm{w}}=w R_{2}=\left\{\Sigma\left[w\left(F_{o}^{2}-F_{c}^{2}\right)^{2}\right] / \Sigma\left[w\left(F_{o}^{2}\right)^{2}\right]\right\}^{1 / 2}$ for all data. 
Table 1. Cont'd.

\begin{tabular}{|c|c|c|}
\hline complex & 4 & 5 \\
\hline CCDC deposit no. & 1460761 & 1460760 \\
\hline color and habit & yellow block & colorless blade \\
\hline size, mm & $0.21 \times 0.21 \times 0.08$ & $0.36 \times 0.09 \times 0.04$ \\
\hline formula & $\mathrm{C}_{6} \mathrm{H}_{5} \mathrm{Cu}_{2} \mathrm{~N}_{5} \mathrm{~S}_{2}$ & $\mathrm{C}_{6} \mathrm{H}_{6} \mathrm{CuN}_{3} \mathrm{OS}$ \\
\hline formula weight & 338.35 & 231.74 \\
\hline space group & $P-1(\# 2)$ & Pnnm (\#58) \\
\hline$a, \AA$ & $5.75360(10)$ & $10.4822(2)$ \\
\hline$b, \AA$ & $6.66110(10)$ & $20.7412(4)$ \\
\hline$c, \AA$ & $7.16720(10)$ & $3.81760(10)$ \\
\hline$\alpha, \operatorname{deg}$ & $103.5560(10)$ & 90 \\
\hline$\beta, \operatorname{deg}$ & $97.6900(10)$ & 90 \\
\hline$\gamma, \operatorname{deg}$ & $110.9560(10)$ & 90 \\
\hline volume, $\AA^{3}$ & $242.097(7)$ & $830.00(3)$ \\
\hline $\mathrm{Z}$ & 1 & 4 \\
\hline$\rho_{\text {calc}}, \mathrm{g} \mathrm{cm}^{-3}$ & 2.321 & 1.855 \\
\hline $\mathrm{F}_{000}$ & 166 & 464 \\
\hline$\mu(\mathrm{Cu} \mathrm{K} \alpha), \mathrm{mm}^{-1}$ & 9.206 & 5.690 \\
\hline temperature, $\mathrm{K}$ & $100(2)$ & $100(2)$ \\
\hline residuals: ${ }^{a} \mathrm{R} ; \mathrm{R}_{\mathrm{w}}$ & $0.0485 ; 0.1279$ & $0.0276 ; 0.0707$ \\
\hline goodness of fit & 1.162 & 1.055 \\
\hline Flack & - & - \\
\hline
\end{tabular}

${ }^{\mathrm{a}} \mathrm{R}=R_{l}=\Sigma|| F_{o}|-| F_{c}|/ \Sigma| F_{o} \mid$ for observed data only. $\mathrm{R}_{\mathrm{w}}=w R_{2}=\left\{\Sigma\left[w\left(F_{o}^{2}-F_{c}^{2}\right)^{2}\right] / \Sigma\left[w\left(F_{o}^{2}\right)^{2}\right]\right\}^{1 / 2}$ for all data. 